\title{
The audience and the star: Genre as the interface and expectation-fulfillment as the catalyst of their relationship
}

\author{
Bikash Ch. Bhowmick \\ Assistant Professor, Department of Media Studies and Journalism, University of Liberal \\ Arts Bangladesh (ULAB). ORCID: oooo-0oo3-0830-1986 \\ Email: bikash.bhowmick@ulab.edu.bd,
}

\begin{abstract}
This article explores the relationship between a film audience and a film star. It assumes that the genre is a common ground or interface where an actor - who then becomes the star, and an audience meet together and afterward the expectations of that audience become the key player to push forward the relationship between them. In forging the relationship between two parties, the genre takes the responsibility of constructing an actor's star-personality and of shaping the spectator's size of a distinct kind. To substantiate the argument, the essay discusses audiences' inscribed entity and construction of a star under the title 'the star - a construction of the negotiations'; the dynamics of their relationship under the title 'audience expectation and their relationship with the Star' and finally, in conclusion, it highlights the genre's intermediary contribution to the relationship. The author has taken the critical/theoretical approach; therefore heavily relied on existing literature and theories (e.g. psychoanalysis, star theory). Primary data has also been used in support of the arguments. Survey questionnaires and in-depth interviews have been used as methods of primary data collection.
\end{abstract}

Keywords: audience, expectation-fulfillment, catalyst, genre, relationship, star

\section{Introduction}

'I am present ... I help it to be born...' (Metz, 1982, p. 93). This Metzian formulation is important to understand the relationship between audiences and stars. Unlike David Bordwell the film and audience studies scholars think that this Metzian "I" is not an actual audience who sees the film sitting before the screen in the darkroom rather this "I" is a construct of the film, an abstraction (Srinivas, 2009). Scholars such as Miriam Hansen, Judith Mayne, and many others call this abstraction the spectator, while S V Srinivas has renamed this abstraction in a different cultural context as a fan-spectator. Srinivas's (2009) reference to Paul Willemen may clarify this complexity emerged from the binary of real viewer/audience and spectator (abstract viewer): this is the fan/viewer inscribed in the film like inscribed reader constructed in by the text, not in history. Srinivas says that it is what the mass film, more generally, the popular film invites its actual viewers to become. According to him, "the structuring of the introductory sequence, in general, and the moment of the arrival of the star, in particular, allows us to see that the film constructs a spectator who knows (about the star but also what to expect), wills (the action) and also trusts (the narrative to provide pleasure by fulfilling expectations)" (pp. 103-104). This alludes to the relationship between the spectator and the star where one side desires and the other fulfills that desire.

(c) AesthetixMS 2021. This Open Access article is published under a Creative Commons Attribution Non-Commercial 4.0 International License (http://creativecommons.org/licenses/by-nc/4.o/), which permits non-commercial re-use, distribution, and reproduction in any medium, provided the original work is properly cited. For citation use the DOI. For commercial re-use, please contact editor@rupkatha.com. 
Nevertheless, the audiences can desire something when they know what to desire, who to desire, and how to desire. As such, a question that might be asked here is: how do they know? They know because they are aware of their taste -'taste is an individual and subjective sentiment' (Ollivier \& Fridman, 2001), and how \& what constitutes this taste. This leads us to John Ellis's argument on how audiences are specified or identified in the film. He argued that the audiences could be specified in two main ways: first through the genre, as it represents the taste of them and second through the star (as cited in Turner, 1999). Contrary to this, the star can only be specified through genre, for example, the personae of Gray Cooper, James Stewart, Henry Fonda, Clint Eastwood are quite distinct, but none of them can be specified/discussed without reference to the concept of the Western (Britton, 1991).

However, for Gledhill (1991), the star is a construct of three components: star as a real person; as a character in the film, and as the star's persona. The third is a combination of the first two but exists independently of a real person or film character. The real person, Gledhill goes on to describe, is the site of amorphous and shifting bodily attributes, instincts, psychic drives, and experiences; and finally, the film character is a construct of film fictional and stereotypical conventions. That is, the star's screen persona gets constituted and also solidified - as s/he repeatedly makes the same kind of characters film after film, through certain means and method of the genre. Therefore, it can be argued that the genre gives birth to a picture personality and hence the star. It accordingly represents the star as a fulfilling site of expectations or wills of the audiences and also outlines the periphery of them.

By outlining the spectators' contour, genre motivates the star(s) to act not how they want to act, but how the spectators want them to act. This postulates that by observing the responsibilities of making an actor star and of shaping the spectator's contour of a distinct kind, genre helps to forge the relationship between them. The sustainability of this relationship between the audiences and the star relies on the degree of fulfillment of audiences' expectations. This essay will explore that the genre as an interfacial space connects audiences with the star(s) and later the expectations of the audiences become the major player to push forward the relationship between them.

\section{The star - a construction of the negotiations}

A general understanding is that not every person can be a star. If it is true, who then becomes a star? According to Violette Morin, stars are thought to be distinct kinds from masses (as cited in Dyer, 1998, p. 43). Adapting the Weberian concept of charisma, Dyer suggests that not all but certain performers become stars, because 'their images embody central but threatened values within a given social conjuncture' (Gledhill, 1991). Charisma in this sense is defined as a 'certain quality of an individual personality by which he [sic] is set apart from ordinary men and treated as endowed with supernatural, superhuman or at least superficially exceptional qualities' (Eisenstadt, 1968; as cited in Dyer, 1991, p. 57). On the charismatic quality of a person, Shils (1965) suggests in 'Charisma, Order and Status':

The charismatic quality of an individual as perceived by others, or himself lies in what is thought to be his connection with some very central feature of his existence and the cosmos in which he lives, and the centrality makes it extraordinary.

This charismatic quality or capacity - in social theorist Bertrand de Jouvenel's (1958) term, 'naked capacity of mustering assent' - dominates the relationship between an individual who possesses that inherent capacity and the masses. This is a capacity, according to Jouvenel, that 'has nothing 
to do with position, or power, or advantage, but emanates exclusively from an inherent personal magnetism' (as cited in Lindholm, 2013, p. 1). The general people, however, categorize this individual as different from the masses. Lindholm (2002) mentions:

When such a person enters a room, heads turn, and those who are without this magical attribute press to be close to the one who has it; they want to be liked by her, to have her attention, to touch her. The hearts of the onlookers' race when the attractive other comes near. This capacity is thus a quality admired and envied; and imagined, perhaps accurately, to lead to success in love and work. In the West, we define and explain this felt magnetic attractiveness of others by referring to it as charisma. (p. 9)

He goes on to say that in western society the romantic relationship is also been shaped by the charismatic capacity of the beloved where the beloved is 'believed by the lover to be special, extraordinary, and remarkable in every way' (p.9). This takes us to the Weberian notion of charisma:

Charisma shall be understood to refer to an extraordinary quality of a person, regardless of whether this quality is actual, alleged, or presumed. 'Charismatic authority', hence, shall refer to a rule over men, whether predominantly external or predominantly internal, to which the governed submit because of their belief in the extraordinary quality of the specific person. (Weber, 1946, p. 295)

Richard Dyer (1991) argues that there are certain complexities about transferring the Weberian political notion of charisma to film theory; but in amended form, the notion of charisma which associates the concepts of social function with an understanding of ideology has particular relevance to star phenomenon.

Dyer's proposition on star personality is valid only when we think star image is a construct of inter-textuality i.e. an on-screen mechanism. More clearly, his approach is grounded in the semiotic form of analysis in which a star's performance in the film is constructed through a combination of signs: visual - the shapes of facial features, aspects of physical build, gestures, hairstyle, costume, etc., verbal - spoken words, non-verbal - voice speed/volume, phrasing. And the star's performance produces the star's on-screen image. Thus, Dyer's proposition about the application of modified Weberian charisma is important here for the construction of the image of a star performer. Star's image can be designated as picture personality ${ }^{i}$.

Now, if it is proposed that the picture personality is an actor's pre-stage of becoming a star, the question is then: how does this picture personality turn out to be a star?

Before looking for the answer to the stated question it needs to be aware of the emergence of celebrity/fame culture which underpins the star system in cinema.

The root of celebrity (culture) can be found back to Roman times when people have a preoccupation with fame and the public person (Braudy, 1986); but "Modern celebrity culture began ... in the eighteenth century when the modern meanings of the words "celebrity" and "star" first became widespread" (Marcus, 2019). Marcus writes, in the eighteenth-century people began showing their interest in persons like authors, artists, performers, scientists, and politicians. Scholars linked this to the historical transformations - the industrial revolution, the emergence of consumer culture. Sennett (2002) argues that with the formation of capitalist, secular and urban society this historical shift brought profound change in persons' public and private life, particularly a declined social engagement, but greater psychic assimilation. He in his book The Fall of Public Man writes: 
The performer's social rise was based on his declaration of a forceful, exciting, morally suspect personality, wholly contrary to the style of ordinary bourgeois life, in which one tried to avoid being read as a person by suppressing one's feelings. (p.27)

According to Grieveson (2002), "Performers became celebrities in a sort of compensatory fashion so that the phenomenon of celebrity is enmeshed with broader changes in social and psychic life." Scholars agree that along with technological development, democratic movements in England, France, and the United States which gave rise to an emphasis on individuality facilitate the celebrity culture (Grieveson, 2002; Marcus, 2019). A series of technological innovations, especially print technology fuel up the celebritism in the early nineteenth century. The innovative Penny Press business tactic - the idea of producing newspapers that sold for a penny -in the 1830s in America contributed enormously to the rise of celebrity culture. Unlike mainstream expensive newspapers, which targeted affluent/elite group, the policy of the penny press was to reach larger audiences, especially the evolving middle and working classes. Accordingly, penny press with its contents gossip, human-interest stories, etc., played a vital role to establish a relationship between performers and audiences and hence helps in the process of creation of celebrity. The theater owners used this vehicle for promoting their performers and production. Film in its early years though represented these theater/vaudeville celebrity performers, can't be considered as film stars. Because Grieveson (2002) mentions:

They were famous for what they did elsewhere; the film simply functioned as a kind of photojournalism or as a way of recording theatrical performances and making it available to a larger number of people. These representations did not then mark out the conditions for the later emergence of the film star, but simply participated in pre-existing celebrations, representations, and structures of celebrity.

According to deCordova (1991), attention was not given to film celebrities until the late 190os. In this early period of the film, patent company/studios were reluctant to circulate the performer's name, his/her special attributes because they thought this would give the performers greater power to grasp the control of the total production mechanism, and together with this, they may demand a higher salary. On June 19, 1905 - the day when the first Nickelodeon opened in Pittsburgh and when the first narrative moving picture The Great Train Robbery (1903) had been screened, the audience watched the film without knowing the actors who brought the story to life. But the total scenario started changing after Florence Lawrence's departure from Biograph to the Independent Motion Picture Company (IMP). Lawrence's move is considered to be the beginning of the star system.

Since then, the studios were compelled to disseminate knowledge about at least lead performers to the audiences as these companies were flooded with pressure from movie-going people. When the studios saw the audiences flexing their economic power by choosing one exhibitor over another because of the picture personality or genres it featured, they started circulating data to the people what they wanted. This opened up the opportunity for a film actor/actress to establish communication, hence the relationship with the audiences, which is vital as audiences' role is inescapable in the creation and maintenance of fame (Douglas \& McDonnell, 2019). Besides, the recurrent appearance of actors in similar genre films and similar kind of role helped to be recognized by the audiences. This tradition of continually casting an actor in similar roles to reinforce a particular image leads to audiences forming emotional attachments to these actors. Along with this generic representation of actor, cinematic styles and techniques particularly known as star-making devices conduce the process of transforming an actor into viewers' ideal 
where the actor is positioned as an object, an eroticized and fetishized icon. For example, the closeup shot - a cinematic device, can make an actor appear larger-than-life and brings the idol close enough to touch (Dyer, 1998). When film after film this idealized person who unceasingly entertains the audiences is stereotypically marketed to them, a personal relationship is built-up between characters (mostly lead character) of the film and audiences. As a result of this, an unending desire is grown up in audiences' minds to know more generally about the lead actor who made the character familiar and beloved. Continuous appearance in a series of stereotypical films which have particular methods and means of conceptualizing reality (Briton 1991) make the actor able to set up his/her kind of myth in accordance with the convention of that genre by which every actor is different from others, even from the actors of his/her own genre. When a myth is set up with the help of genre convention and charisma, an image has been built up, which is, in Dyer's word, known as star image and when, according to Gledhill (1991), actor's off-screen lifestyles and personalities equal or surpass its image produced through a complex mechanism of genre's codes \& conventions, cinematic techniques and actor's charismatic ability, an actor becomes a star. This points to the actor's association with cinema begins through a genre. His/her every action from the first appearance on screen to at least building of a popular image mediates in accordance with the genre's means and methods. The same is observed in the South Asian context. Amitabh Bachchan's 'angry young man' screen image in the 1970s and 1980 cannot be thought of without a certain genre which has constituted his distinctive picture personality. Early-stage of his career, before 1973, he had been a minor artist who was relatively unknown and hardly got space in film magazine (Vitali, 2008). Zanjeer/The Chain (Prakash Mehra 1973) was the first film that brought Bachchan to light. The film which belongs to the 'Gangster' genre constituted the basement of his future picture personality. Deewar/Wall (Yash Chopra, 1975), Sholay/Flames of the Sun (Ramesh Sippy, 1975) and Muqaddarka Sikandar/The Emperor of Fate (Prakash Mehra 1978) were the three consecutive similar genre films which firmly leveled his 'angry young man' screen image (Kavoori \& Punathambekar, 2008; Vitali, 2008). Similarly, most of the stars are/were associated with certain genres, such as, John Ford and John Wayne are linked to the Western; Mae West, W.C. Fields, the Marx Brothers, Bob Hope, and Bing Crosby had an association with Comedy and so on. During the classical era, not only stars but also studios were renowned for the certain genre: Paramount excelled in comedy; Warner Bros. developed a reputation for gritty social realism, ranging from gangster pictures to war pictures and Westerns; 2oth Century Fox forged the musical and many prestige biographies; etc. Some actors of course latterly become a star of cross genres. But in this case, s/he was associated with a particular genre at a particular stage of her/his career (for example, Garbo) and later s/he moves out to another genre \& constitute a new identity which is also genre-specific (Britton, 1991). Albeit some major stars are simultaneously associated with several genres, but the identification of these actors with the genre cannot be neglected.

\section{Methods}

To substantiate the argument, the author has taken a critical/theoretical approach; therefore heavily relied on existing literatures and theories (e.g. psychoanalysis, star theory). Primary data has also been used for the solidification of the argument. Survey questionnaires and in-depth interviews have been used as methods of primary data collection.

Surveys and in-depth interviews have been conducted among 82 cinema-viewers ( 72 survey respondents; 10 in-depth interviewees) living in Dhaka, the capital city of Bangladesh. The reasons for selecting survey respondents from Dhaka are a) one-eighth of the total population of the country lives in Dhaka; b) Dhaka is the hub of employment, people migrate from all parts of the country to 
Dhaka for livelihood and stay here-; hence there is a good representation of the people from every corner and c) Dhaka has the highest number of cinema halls and/or multiplexes.

For conducting surveys and interviews the author and/or his research assistant visited crowded places (shopping malls, theaters/multiplexes, parks, and lakeshores) of Dhaka. During selecting survey or interview respondents it was made sure that the participants are the regular viewers (viewers who watch a film at least every month) of cinema.

\section{Audience expectation and their relationship with the star}

The relationship between lover \& beloved reminds us Lacanian psychoanalytic theory of identification. In Lacanian psychoanalysis, the term Father is associated with charisma. When the father's child enters into the language, it can imagine the inherent domineering power, inherent personal magnetism of authoritative father, and admittedly obeys the father's will for not to desire for its mother. At the very moment when the father's child is resisted by the name of the father, it starts imitating its father - a personality constituted before the child is charismatic, and ultimately possesses a father's position. Here, the child is identified with a father as a lover identified with a beloved. Once when it adapts father's language i.e. internalize father's charismatic quality, it takes the position of the father in the name of the father and becomes visualized as charismatic to its child. This is a cycle (father - child - father - child - ...) that continues forever.

If we don't complete/continue the cycle, i.e. if we stop cycling (father - child - father) after the first transformation of the child into father, a new concept [father (star) - child (viewer) - father (inscribed viewer/spectator)] emerges out of this which has some relevance to the recent theory of star-audience/spectator relationship, unlike past. In this new formulation, a star as father invites viewers (child) to be the child (passive viewer) of him/her, a mere recipient of the character s/he has made in the film. The difference between the Lacanian child and the viewer is that the Lacanian child loses control immediately after the tenure of its fatherhood to its child who has taken the position of the father; but the viewer never loses its control over the star when it becomes the inscribed viewer. This offers us a very different notion of spectatorship where by no means the viewer remains in a passive position as it would have been in the early days of its relationship with the star. This takes us back to Metzian famous formulation mentioned at the very outset in this paper: 'I am present ... I help it to be born...' At the superficial level, it seems that the spectator is identified with the star as in Lacanian psychoanalysis the child is identified with the father. This Lacanian identification points to the subordination to one's superior. The relationship that exists there is a power relationship. But if one looks at the relationship between the star - industry image and the spectator - inscribed viewer deeply, s/he might see something different is happening. This relationship is not an identification (superior-inferior). In this new proposed relationship, Lacanian model does not work. Because, when an actual viewer once becomes an inscribed viewer/ spectator of a certain genre and actor/star, it never forgets its earlier viewing experiences. Recalling all those experiences the viewer inscribed in the film always wants the star to do how it tells the star to do. It is surprising that in the film the spectator does not ask the story character, who it does not know, to do; it calls the person in the film who it met several times before in the same situations and who always listened to it. This argument rejects the concept of spectator's (inscribed viewer) identification with the star, rather proposes a relationship between the star and the inscribed viewer. The future of this relationship completely relies on the will of the viewer. In this relationship, one side (viewer) expects or desires and the other side (star) has only an option which is to fulfill that expectation(s) or desire(s). This screening-time interaction has a great influence to shape the relationship between the actual viewer/ audience and the star. The actual viewer does 
not forget what had happened in the last film watching. And, this recent experience helps him/her whether s/he will watch the next film of the same actor/star.

The empirical data support this strongly. 69.44 per cent of the survey respondents report that the previous experiences of film-watching help them to select the next film to watch. This indicates that not the performer, the performance of the performer (star) is the key to their relationship. If so, a question might be asked: why do the viewers have their favorite star? Or, why do they love to watch their favorite stars' films one after another? The interviewees who have their favorite star articulate that the certain actor(s) and/or actress(s) has become their favorite because of their performance they have executed film after film. According to the interviewees, the presence of their favorite star(s) guarantees that the money they invest for watching the film(s) will be worthy of. They are confident about the performance of their favorite star(s), about the story of the film(s). An interviewee categorically responds [all quotations translated from Bengali]: "Before watching a certain film, some predetermined expectations grow in me from the earlier experience of film watching, and I also know that the cast who I came across several times before will fulfill all my expectations." Another interviewee delineates:

The big thing for which I watch my favorite star(s) films is the performance. Because, when you watch a film, you watch the performance through which the director tells the story. Sometimes it happens that due to the brilliant performance of the performer, a film with a weak story becomes successful.

One stresses, “... see, when you like a film of an actor, you might watch his next film(s) expecting the same performance." The other interviewee explains, "Stars are like a brand. The movies in which they play the roles are good. And therefore, people unhesitatingly watch their films."

However, not every actor becomes the favorite of a certain viewer, a certain actor(s)/actress(s) becomes a favorite of a certain viewer(s). Because a star can't satisfy all the viewers as satisfaction is individual specific. An interviewee who claims to have been a fan of a Bangladeshi action-superstar Manna (December 6, 1964 - February 17, 2008) doesn't like to watch films of present action-superstar of Bangladesh film industry Shakib Khan. According to him, the way Manna performed, delivered dialogue, rescued heroin was unbelievable. "I didn't find anyone who can do in the same way Manna did...For this, I don't like any Bangladeshi actor”, he mentions.

Many of the interviewees and survey respondents express that establishing trust in the minds of audiences is inevitable for a star to be continually successful. Rajadhyaksha (200o) rightfully argues that "an already formed spectator, who exists before the film is made and shown, enters a movie theatre with considerable guarantee... and identifies with - not the film's hero or heroine - but with himself, his 'inscribed' self' (p. 284). This is a self that has been formed with a profound negotiation between viewers' wills and star's performances. Rajadhyaksha goes on to write that when the viewer purchases a ticket, enters the auditorium, within a couple of minutes $\mathrm{s}$ /he becomes the subject of the film content by entering into the on-screen mechanism where his physicality is wholly absent i.e. unseen. This unseen entity of the viewer in the film diegetic world is known as, in Rajadhyaksha's term, inscribed viewer, and in S V Srinivas's (2009) term, fanspectator. Willemen (1994) draws our attention to the gap between two other entities - real and inscribed readers which correspond with the viewer (actual) and spectator (inscribed viewer). Willlemen's notion of a distinction between real and inscribed readers allows us to say that the spectator of the film is not a real (actual) viewer. The motive is not to disagree with this proposition of differentiation; rather suggest that though the actual viewer and the spectator (inscribed viewer) are two separate entities, but, one cannot be thought of without the other. Because the inscribed 
viewer is none but the screen-self of the actual viewer and this screen-self in the film diegesis has a profound influence in shaping the relationship between an actual viewer and a star outside the theatre.

At this point a question might be asked: how is actual viewer's this screen-self been constructed? Or, does the fulfillment of audiences' expectations by the star contribute to this construction of the viewer's screen-self?

This leads to another question: why do these audiences go to the theatre to watch a particular film of a particular actor? Drawing from Srinivas's Megastar it can be argued that the audiences go to the theatre because the action of the actor in the film is presented as if it is a direct consequence of the will of them. That is, the particular actor (the star) acts like the audiences want him to act. This points to a pattern of relationship between the star and the audiences, a relationship of expectation and fulfillment of expectation. Film after film by fulfilling the expectations, the star invites its audiences for a perpetual relationship within and outside of the theatre.

Let me propose two models of how audiences and actors (leading actor in particular) fall into a relationship. One model is for the first-time film viewer and the second is for the regular viewer. The primary communication between the actor (in general)/star (in particular) and audiences, as Christine Gledhill (1991) writes, comes about through the actor's/star's body. Photography - especially the close-up, Gledhill reference to S. McKnight, offers audiences a gaze at the bodies of the actor and more sustained than the majority. Bela Balazs theorizes, Gledhill continues, 'the close-up on the actor's face as a 'window of the soul". That is, the actor reaches their audiences (fresh or regular) through his/her body. If the first interaction between them get succeed, i.e. if the audience's - fresh (fresh in a sense that these audiences may be the first time film goer or maybe the regular goer for a certain genre, but first time viewer for another genre film) or regular, expectations get fulfilled, the second level of interaction gets started. In other words, the language of this particular film by which a star is born negotiated to constitute its audiences. As a consequence of the cinematic language of a particular kind and the actor's charismatic appearance, the audience's expectations arrive at this level. According to Srinivas (2009), at the second level of the relationship, the audiences become the subject and the star appears because the audiences will him to do so. Srinivas goes on to depict that in the film Bhadrachalam (N Shankar 2001), the lead character Bhadrachalam will not get up unless the audiences will him to do this. This means that the audiences reach a deeper level of relationship with the star. An audience at this juncture becomes a regular viewer of films of a certain star with two separate existences (actual viewer and screen-self of the actual viewer) in a soul. Viewers' screen-self (inscribed viewer) bridges the relationship between a star and an actual viewer and the relationship sustains till that moment the star can respond to the wills/expectations of the inscribed viewer(s). The resonance of the fulfillment of the inscribed viewer's wills or expectations invites its actual-self (real/actual viewer) to watch the immediate-next film of the same star. 41.67 per cent of a total of 72 survey respondents have replaced their beloved star's name from the list of a favorite with a new name, of whom 60 percent did this due to the decadence of their favorite stars' performance, 6.67 percent for the death of their favorite stars and 30 per cent didn't mention the reasons for replacement. The audiences believe that film watching is a kind of investment (buying a ticket and spending $2 / 3$ consecutive hours); therefore, it is natural to expect something from the film, especially from the star for whom they are investing their money and time, in return. Failing to meet what audiences will/expect causes harm to the relationship. An interviewee firmly articulates: 
If my favorite star consecutively disheartens me, i.e. if after a certain point of time he starts failing to meet all my aspiration I set just before watching every of his films, the trust that has been grown gradually in my mind due to his brilliant performances film after film and depending on which our relationship has been built up or basing on which I became a fan of him might transform into distrust.

In response to the query - what will you do if your favorite star continuously disheartens you film after film? - another interviewee empathically explains:

I might continue watching some of his bad films as well, but how long? Assume that I have decided to watch a film. And to do so I need to spend money and time also. I can't afford his bad performance day after day. Of course, I will give him time for a return, but it is not for an infinite time.

The extract from an interview with a study respondent below might help us to comprehend a cinema viewer's approach to the relationship between an audience and a star:

Interviewer: Suppose, for some unavoidable reasons, you were unable to watch your favorite star or actress's film on the first day of releasing the film. But one of your close friends watched it and gave negative feedback to you saying that it's a horrible film. What will you do after listening to this? Will you go to watch the movie?

Study Respondent (SR): I will go.

Interviewer: Why?

SR: ... because he is my favorite star. My friend might not like the film due to some reasons, he might have different expectations and point of view. The reasons for which my friend has disliked the film may not be the same for me. Whatsoever, I will watch it, because it is my favorite star's film.

Interviewer: Okay, assume that you have watched the film and you have found your friend's statement was true. The film truly has disheartened you. What will be your feeling?

SR: My feeling would be of course very bad because my expectations were not fulfilled. It is however difficult for a star to make his fans happy in all the films.

Interviewer: Two or one years later if another film has been released, what your decision would be then?

SR: I will wait, I will wait for some days for reviews. I believe that he will do well in this film ... I will decide after looking at all the reviews.

Interviewer: If the reviews that you will have received from the first to the fifth day's audiences are mixed, mostly bad reviews, what will you do?

SR: I will go to the movie. At least I have some hopes, as there are some good reviews.

Interviewer: Say, you have gone to the cinema and you found the film not satisfactory...

SR: What can I do then? I might feel bad. I will criticize.

Interviewer: Last two consecutive films of your favorite star have disheartened you. What will you do when his next film will be released sometime later? 
SR: I believe that he will have a strong come-back. His two films were unsuccessful successively. He will then be cautious about selecting a film(s) and must try to recover his image. I will surely watch it.

Interviewer: Well. Again, assume that after the massive downfall due to three unsuccessful films your favorite star comes up with another film. The reviews were comparatively good. You went to the theatre and watched the film. But you didn't fully find the reflection of the reviews, i.e. this film also failed to satisfy your expectation. What will you say then?

SR: I will have nothing to say. I will be upset. One thing must happen: the trust that has been built up due to his brilliant performances will fade away... I may not continue watching his film.

Interviewer: If so, what is the relationship between you and your favorite star?

SR: The relationship between us was built up due to his works. We all watch our favorite stars' films, praise them, clap them for their performances, and at the same time our expectation grows up. On the other hand, if they fail, we in different ways create pressure on them. But if my favorite star continually fails to perform, I may stop watching his film(s).

Interviewer: That means, based on your statement couldn't I conclude that whose films you will continue watching depend on whether your expectations are being fulfilled?

SR: Yes... this is a psychological matter. When an actor does well, we are with him, but from a point of time if he fails to fulfill our expectations film after film, we can't afford to support him.

The majority of in-depth interview respondents echo almost in a similar fashion. A mid-aged respondent who occupies a mid-level position in a government office opines that "people watch cinema with a considerable expectation. And if these expectations remain unfulfilled recurrently, it is obvious then that the devoutness toward one's favorite star decreases inchmeal despite all good memories the audience had to have with the star." Another respondent asserts that "the prime task of a movie star is to entertain us. If s/he can't do that, why should I waste my time watching her/his movies?"

\section{Conclusion: genre - the interface}

Genre is an important feature in the process of constructing stars' screen personality (elaborately discussed in the section entitled 'The star - a construction of the negotiations') and likewise, it is as well one of the determinants of the audience's choice for a film, not only in terms of whether or not they possess the competencies to appreciate that genre but in terms of what kind of film it is they want to see (Turner, 1999). In a study, it is found that genre preference as well as stars have had a high influence when they (95 per cent) select a movie to watch (Maxfield 2003). Referring to John Ellis, Turner (1999) mentions that there are two ways to specify audiences: through the genre and stars. Audiences choose movies through their representations in the press and on television, and through conversations and other social contacts, and those representations are understood in terms of genre and/or star (p. 117). Many scholars express a similar view regarding viewers/readers' choice of a particular text. John Corner writes that 'genre is a principal factor in the directing of audience choice and audience expectation' (as cited in Chandler, 1997, p. 8). It, as 'the product of a text- and audience-based negotiation activated by the viewer's expectation' (Creeber, 2001, p.7), provides viewers the point of departure for a film and act as a quasi-search feature through which the 
audiences evaluate the traits of the product without having seen that product (Hennig-Thurau, Walsh \& Wruck, 2001). McKee rightly argues that 'the audience is already a genre expert. It enters each film armed with a complex set of anticipations learned through a lifetime of moviegoing' (1997, p. 8o). Therefore, an audience must pick a genre(s) relying on his/her personal choices and experiences. A teenage audience may choose a horror film because $s /$ he wants to be scared and feel the thrill of an adrenaline rush ("Audience and institution," n.d.). This teenager shall never choose a star who acts for a romantic film unless s/he has a preference for the genre. The same teenager who loves to watch a romantic film might go for a romantic hero, as his/her emotional arousal can only be mitigated by a romantic hero. This alludes that the audiences' preference for a genre(s) and their favorite stars' genre(s) affiliation match together. The survey data strongly support this conceptualization. The respondents' preferences for the genre(s) have a strong correlation with their favorite stars' genre(s) affiliation. The survey data reveals that 98.61 per cent of the respondents prefer a star(s) as their favorites who have acted for the genre(s) they like. This empirical data supports Phillips's (2007) argumentation on the function of genre. He mentions that the genre helps audiences to become orientated, to navigate their way through the world of the film about familiar traits. This means that due to the certain specificities of genre(s) film audiences already know what they will be offered and what they can expect! McQuail (1987) correctly claims genre as a practical device for helping mass media to produce constantly and efficiently and to relate its products to the expectations of its consumers, in the same way how it does enable individual media users to plan their choices.

\section{End Note}

iWhen an actor performs in a series of stereotypic films, a particular image of that actor is built up through the signs he presents and the meanings he generates together with the combination of signs to her/his audiences; and this constitutive image is known as picture personality (see also Dyer, 1998; Gledhill, 1991).

\section{References}

Audience and institution in relation to genre. (n.d.). Retrieved from

https://sites.google.com/site/mediafoshaw/research/audience-and-institution-in-relation-to-genre

Braudy, L. (1986). The frenzy of renown: Fame E its history. New York: Oxford University Press.

Britton, A. (1991). Stars and genre. In C. Gledhill (ed.), Stardom: Industry of desire (pp. 199-206). London and New York: Routledge.

Chandler, D. (1997). An introduction to genre theory. Retrived from https://faculty.washington.edu/farkas/HCDE5ıFallzo12/Chandler_genre_theoryDFAnn.pdf

Creeber, G. (Ed.). (2001). The television genre book. London: BFI

deCordova, R. (1991). The Emergence of the star system in America. In C. Gledhill (ed.), Stardom: Industry of desire (pp. 17-29). London and New York: Routledge.

Douglas, S. J. and McDonnell, A. (2019). Celebrity: a history of fame. New York: New York University Press.

Dyer, R. (1991). Charisma. In C. Gledhill (ed.), Stardom: Industry of desire (pp. 57-59). London and New York: Routledge.

Dyer, R. (1998). Stars. London: British Film Institute.

Gledhill, C. (Ed.). (1991). Stardom: Industry of desire. London and New York: Routledge.

Gledhill, C. (1991). Signs of melodrama. In C. Gledhill (ed.), Stardom: Industry of desire (pp. 207-229). London and New York: Routledge. 
Grieveson, L. (2002, September 20). Stars and audiences in early American cinema. Screening the Past. http://www.screeningthepast.com/issue-14-classics-re-runs/stars-and-audiences-in-early-americancinema/

Hennig-Thurau, T., Walsh, G. \& Wruck, O. (2001). An investigation into the factors determining the success of service innovations: the case of motion pictures. Academy of Marketing Science Review, 1 (6), 1-23. Retrieved from https://www.researchgate.net/publication/237721612

Jouvenel, Bertrand de 1958: Authority: The Efficient Imperative. In C. Friedrich (ed.), Authority, Cambridge MA: Harvard University Press.

Kavoori, A., \& Punathambekar, A. (Eds.). (2008). Global Bollywood. New York; London: NYU Press.

Lindholm, C. (2002). Charisma. Retrieved from http://diffpsychology.narod.ru/olderfiles/1/charisma.pdf

Lindholm, C. (2013). Introduction: Charisma in theory and practice. In C. Lindholm (ed.), The anthropology of religious charisma - Ecstasies and institutions (1-30). New York: Palgrave Macmillan.

Marcus, S. (2019). The Drama of Celebrity. Princeton University Press.

Maxfield, S. M. (2003). Media at the movies: Analyzing the movie-viewing audience. Retrieved fromhttp://etd.fcla.edu/UF/UFEooo156o/maxfield_s.pdf

McKee, R. (1997). Story: Substance, structure, style and the principles of screenwriting. New York: Regan Books

McQuail, D. (1987). Mass communication theory: An introduction (2nd edition). London: Sage Metz, C. (1982). Psychoanalysis and cinema: The imaginary signifier. London: Palgrave Macmillan.

Ollivier, M and Fridman, V. (2001). Taste and taste culture. In N. J. Smelser and P. B. Baltes (eds.) International encyclopedia of the social \& behavioral sciences, Pages 15442-15447. Retrieved from https://www.sciencedirect.com/referencework/9780080430768/international-encyclopedia-of-thesocial-and-behavioral-sciences

Phillips, P. (2007). Genre, star and auteur critical approaches applied to Martin Scorsese's New York, New York'. Retrieved from http://cw.routledge.com/textbooks/9780415409285/resources/genrestar.pdf\#page=1Ezoom=auto,o,8oo.

Rajadhyaksha, A. (2000). Viewership and democracy in the cinema. In R. S. Vasudevan (ed.), Making meaning in Indian cinema (pp. 267-19).New Delhi: Oxford University Press.

Sennett, R. (2002). The fall of public man. London: Penguin Books

Shils, E. (1965). Charisma, order, and status. American sociological review, 30(2), 199-213. Retrieved from https://www.jstor.org/stable/2091564

Srinivas, S. V. (2009). Megastar: Chiranjeevi and Telugu cinema after N. T. Rama Rao. New Delhi: Oxford University Press.

Turner, G. (1999). Film as social practice. London: Routledge.

Vitali, V. (2008). Hindi action cinema - Industries, narratives bodies. New Delhi: Oxford University Press. Weber, M. (1946). From Max Weber: Essays in Sociology. (H. Gerth and C. W. Mills, Trans. \& Eds.). New York: Oxford University Press.

Willemen, P. (1994). Looks and frictions : essays in cultural studies and film theory. Bloomington : London: Indiana University Press, British Film Institute.

Bikash Ch. Bhowmick is an assistant professor in the Department of Media Studies and Journalism at the University of Liberal Arts Bangladesh (ULAB). He previously taught at Stamford University Bangladesh. His research interests include: star and audience studies, screenwriting research, and women and cinema. 